\section{D) Check for updates}

Cite this: Chem. Commun., 2019, 55,3859

Received 17th December 2018 Accepted 6th March 2019

DOI: $10.1039 / c 8 c c 09982 k$

rsc.li/chemcomm

\title{
Nanocontainer-based self-healing coatings: current progress and future perspectives
}

\author{
Elena Shchukina, ${ }^{a}$ Hongqiang Wang (D) bc and Dmitry G. Shchukin (D) *ac
}

\begin{abstract}
Here, we summarize the recent achievements in the field of the nanocontainer-based self-healing coatings made during the last 8 years. The development of nanocontainer-based self-healing coatings was started 15 years ago from the study of nanocontainers with stimuli-responsive release properties able to release anticorrosion agent (inhibitor) on demand only into a corroded area thus preventing its spontaneous leakage. Since then, many different types of nanocontainers have been demonstrated: from polymer capsules to porous inorganic nanoparticles with sophisticated mechanisms of release triggering. Nowadays, the study of the commercial application of nanocontainer-based self-healing coatings is the main focus in this area, especially for coatings with several autonomic functionalities. However, the search for the new types of multifunctional nanocontainers possessing different triggering mechanisms still remains active, especially for low-cost natural nanocontainers.
\end{abstract}

\section{Introduction}

More and more new automated systems have influenced the economy and human life during the last 50 years. Most of

${ }^{a}$ Stephenson Institute for Renewable Energy, Department of Chemistry, University of Liverpool, L69 7ZF Liverpool, UK. E-mail: d.shchukin@liverpool.ac.uk

${ }^{b}$ Centre for Nanoenergy Materials, School of Materials Science and Engineering, Northwestern Polytechnical University, Xi'an, 710072, P. R. China

${ }^{c}$ Joint UK-China laboratory on Advanced Nanomaterials for Energy Applications, School of Materials Science and Engineering, Northwestern Polytechnical University, Xi'an, 710072, P. R. China

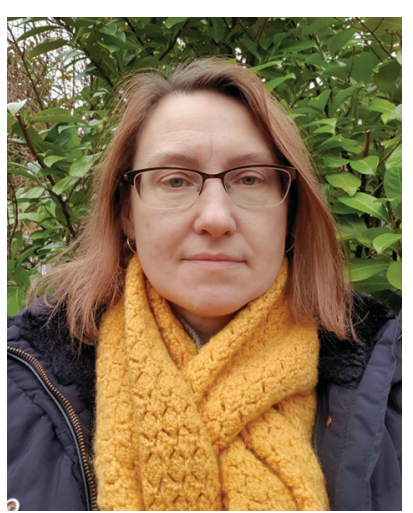

Elena Shchukina
Dr Elena Shchukina received her PhD in Organic Chemistry (2008) at the Belarussian Academy of Sciences, Belarus. She has gained experience in organic chemistry working in different industrial companies. Since 2015, she is project leader in the Stephenson Institute for Renewable Energy, University of Liverpool, working on the encapsulation of corrosion inhibitors, biocides and materials for thermal energy storage.

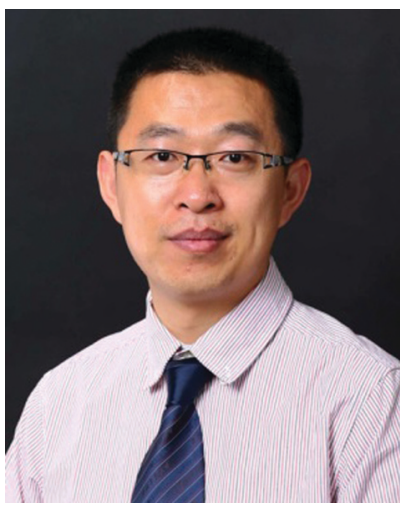

Hongqiang Wang them, of course, are related to the very rapid progress that there has been in computing technologies which has changed the information environment of humans. Unfortunately, the development of smart materials with self-responding properties on the micro- and nano-scale was started much later in the 1980s. Here, we would like to highlight one of the universal approaches for the fabrication of autonomous materials based on the encapsulation of active agents into micro- and nanosized containers (capsules) with controlled release properties of the shell. This approach can be applied to different types of smart materials with multiple responsive functionalities. Science and Technology (Japan), Max Planck Institute of Colloids and Interfaces (Germany), and University of Liverpool (UK). His research interest has been on the study of transient extreme conditions including pulsed laser irradiation and ultrasonication for generating novel functional materials in energy applications. 


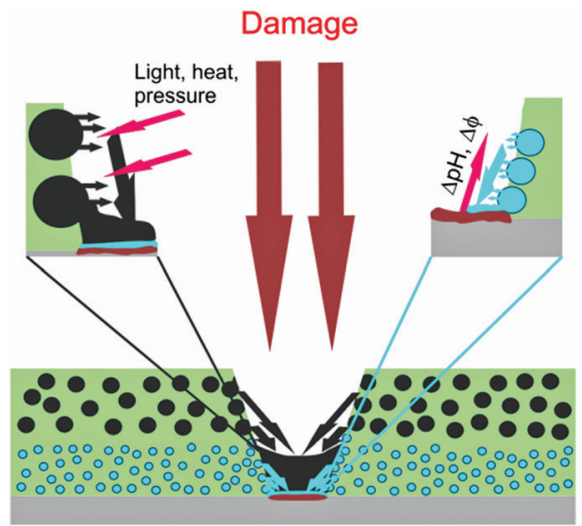

Fig. 1 Concept of nanocontainer-based self-healing coatings. ${ }^{2}$

However, due to the main expertise of the authors and limited journal space, we focus this Highlight on nanocontainer-based self-healing coatings.

The concept of such a type of coating combines the classic passive component of the coating matrix (layer) and an active component, i.e. nanocontainers with controlled permeability of the shell and loaded with corrosion inhibitors or other active agents (Fig. 1). ${ }^{1,2}$ This allows one to combine in one coating classical passive functionalities like barrier or colour, together with active ones that are responsive to both internal and external impacts like cracks, local $\mathrm{pH}$, electrochemical potential, temperature, humidity. The use of nanocontainers as a coating pigment will provide a breakthrough in the current coating technologies making the coatings: (a) autonomic, self-repairing of cracks and thus enhancing the corrosion protection of the metal substrate, (b) more durable with increased maintenance time, and (c) multifunctional with additional active functionalities, e.g. sensing, antifouling, etc.

The main target in the "nanocontainer" approach is to develop a nanocontainer shell with controlled permeability that is specific to several triggers whilst, at the same time, being stable inside the coating formulation as well as during coating application and curing. Another important step is the

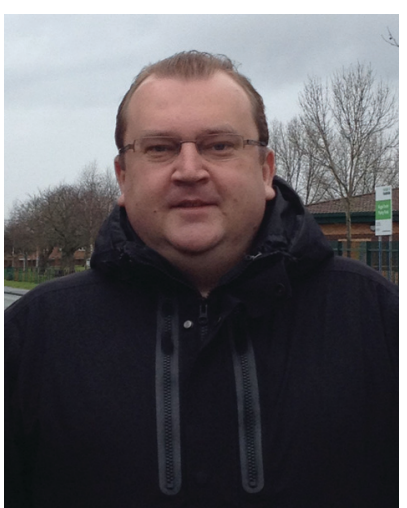

Dmitry G. Shchukin
Prof. Dmitry Shchukin was a group leader at the Department of Interfaces, Max Planck Institute of Colloids and Interfaces, Potsdam, Germany, in 2007-2012. He obtained his PhD (2002) in Physical and Inorganic Chemistry. Currently, he is Professor in Chemistry, Stephenson Institute for Renewable Energy, University of Liverpool. His main research expertise is the encapsulation of energy materials and chemistry at the cavitation interface. uniform distribution of the nanocontainers in the coating. The formation of the any aggregates will (i) damage the coating integrity and performance in the aggregated area and (ii) leave some parts of the coatings without self-healing ability. The content of the nanocontainers in the coating also influences the coating performance. If the quantity of the nanocontainers is too large, the coating performance (e.g., colour, adhesion) can drastically drop. It has been demonstrated experimentally that the nanocontainer concentration should not exceed $10 \%$, with $5 \%$ being the most optimal concentration. ${ }^{2}$

Mechanical impact was the first external stimulus demonstrated for capsule-based self-healing coatings by the group of S. R. White in $2001 .^{3}$ They encapsulated a healing agent (dicyclopentadiene) into polymer microcapsules embedded in an epoxy matrix containing Grubbs catalyst. Embedded microcapsules were ruptured inside the coating crack, releasing the healing agent which entered into contact with the embedded catalyst. The resulting polymerization of the healing agent leads to crack healing and recovery of the barrier properties of the coating. Simultaneous incorporation of two types of capsules containing different active agents ${ }^{4}$ or capsules filled with reactive epoxy resin or oil ${ }^{5,6}$ have also been reported. Encapsulation of moisture or oxygen reactive materials, such as metal oxide precursors, ${ }^{7}$ or linseed oil $^{8}$ adapts nanocontainer response to atmospheric oxygen or humidity forming an impermeable layer in the damaged part of the coating.

The $\mathrm{pH}$ shift occurring on the metal substrate surface during the corrosion process is the second, and now most popular, trigger studied for self-healing coatings for corrosion protection. The corrosion process is associated with a local $\mathrm{pH}$ decrease in the anodic area and a local $\mathrm{pH}$ increase in the cathodic one. Therefore, the nanocontainer shell that is sensitive to either both or one of acidic and alkaline regions can release encapsulated inhibitor for corrosion termination. Polyelectrolyte capsules, ${ }^{9}$ polymeric micro/nano-sized capsules formed by interfacial polymerization, ${ }^{10}$ hydrogels ${ }^{11}$ and porous nanoparticles with bioinspired nanovalves ${ }^{12-15}$ having weak acidic or basic functional groups in the shell have been presented in the literature for reversible and (or) irreversible changes of the shell permeability in a wide $\mathrm{pH}$ range.

More rare external triggers used for capsules and nanocontainers in self-healing coatings are: (1) electromagnetic irradiation, where the container shell should have sensitive components like metal nanoparticles that are responsive to IR light, ${ }^{16}$ dyes for visible light ${ }^{17}$ and $\mathrm{TiO}_{2}$ nanoparticles for UV light; $;^{18,19}$ (2) ultrasonic treatment; ${ }^{20}(3)$ temperature $;^{21}$ (4) ionic strength $;^{22}$ and (5) the electrochemical potential on the surface of the corroded metal. ${ }^{23-25}$

The current level of development of nanocontainers for selfhealing coatings with single functionality or that are responsive only to one triggering mechanism has already achieved a sufficient number of demonstrations on the laboratory scale and now requires steps for industrial implementation using low cost, effective nanocontainers. The presented Highlight paper is a follow-up to our first Highlight paper in the area of nanocontainers and self-healing coatings published in $2011 .^{26}$ 
Our Highlight surveys two main trends in the further progress of nanocontainer-based coatings: the commercialisation of currently existing technologies and development of the second generation of the self-healing coatings possessing multifunctionality, active to multiple triggering mechanisms.

\section{Nanocontainers for industrial application in self-healing coatings}

All nanocontainers (capsules) can be divided into two classes by their nature: polymer nanocontainers (core-shell capsules, gels) and inorganic nanocontainers (porous inorganic materials). Polymer nanocontainers require multi-step technology for their fabrication including polymerisation reactions, encapsulation of inhibitor, washing, removal and utilization of the reaction by-products and non-reacted reagents. Their fabrication also requires quite sophisticated equipment. On the contrary, commercially available porous inorganic materials can be directly applied as inorganic nanocontainers for self-healing coatings. Only inhibitor loading and the formation of trigger-sensitive blockers (nanovalves) are the fabrication steps that are needed to produce ready-to-use inhibitor-loaded nanocontainers. Inorganic nanocontainers could be mesoporous silica ${ }^{27}$ or titania, ${ }^{28}$ ion-exchange nanoclays ${ }^{29}$ and halloysite nanotubes. ${ }^{30}$ Mesoporous silica and titania are commercial products and, despite the fact that they are produced in volumes of thousands of tons, they are still more expensive than raw materials: ionexchange clays and halloysites. The last two types of nanocontainers can be mined from different deposits and used after purification for inhibitor loading and further as self-healing additives in coatings.

\section{Ion-exchange nanoclays as nanocontainers}

There are two types of ion-exchange release of the entrapped inhibitor from nanoclays: the less studied cation-exchange release and the more developed anion-exchange release. ${ }^{31}$ Both of them have a similar mechanism of uptake and release of the corrosion inhibitors that are loaded between the layers (Fig. 2). The only difference is in the triggers that initiate the release.

If the nanoclay layers are negatively charged, only a positively charged inhibitor can be uploaded in the interlayer galleries to compensate the negative charge. The same mechanism exists for positively charged nanoclay layers - only a negatively charged corrosion inhibitor can be uploaded. The release of nanoclaybased nanocontainers is triggered by ion-exchange in the presence of $\mathrm{H}^{+}, \mathrm{OH}^{-}, \mathrm{Cl}^{-}$and other corrosion products or aggressive ions. ${ }^{32}$

However, the release of the inhibitor in cation-exchanger clays can only be triggered by metal cations available in the surrounding environment, which may not be directly associated with corrosion processes leading to the uncontrolled release of the inhibitor. Bentonite is a cation-exchanger and a rare example of a nanocontainer for self-healing coatings, consisting of stacks of negatively charged aluminosilicate sheets between which inhibiting cations like $\mathrm{Ca}^{2+}$ and $\mathrm{Ce}^{3+}$ are intercalated. ${ }^{33}$

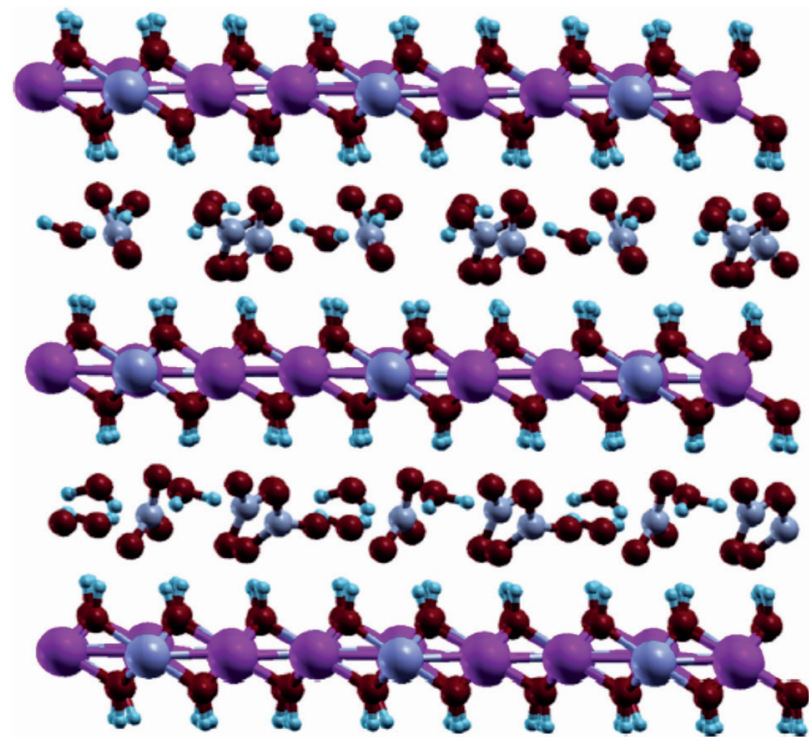

Fig. 2 Schematic presentation of the layered nanoclay structure. ${ }^{31}$ Inhibitor molecules (small) are uploaded within interlayer galleries between nanoclay layers.

When dispersed in polyester resin layers and applied to galvanized steel substrates, Ce-loaded bentonites display active protection and avoid coating decomposition. The protective performance of Na-montmorillonite (Na-MMT) intercalated with zinc cations (Zn-MMT), benzoimidazole (BIAMMT) and a mixture of these two inhibitors (Zn-MMT + BIAMMT) is described as an example of another cation-exchanging natural clay material for self-healing anticorrosion coatings. ${ }^{34,35}$ The highest corrosion resistance and the lowest adhesion loss were observed when a mixture of Zn-MMT and BIAMMT clay nanocontainers was used. The crack filling behaviour of a transparent, multilayer coating consisting of a polysiloxane film on top of a thin montmorillonite interlayer was monitored using confocal and SEM microscopy. ${ }^{36}$ Beyond a $2 \mathrm{~h}$ healing period, further expansion of the clay layers resulted in the restoration of the barrier properties of the coating.

The anion-exchanging clays are more effective in controlling the behavior of the corrosion inhibitor in the coating. For anion-exchange clays, not only the release of the corrosion inhibitors but also the trapping of the corrosive agents $\left(\mathrm{Cl}^{-}, \mathrm{SO}_{4}{ }^{2-}\right)$ are efficient for autonomic corrosion protection. Layered double hydroxides (LDHs) have the general formula $\left[\mathrm{M}_{1-x}{ }^{2+} \mathrm{M}_{x}{ }^{3+}(\mathrm{OH})_{2}\right] \mathrm{A}_{x / n}{ }^{n-} \cdot m \mathrm{H}_{2} \mathrm{O}$, where the cations $\mathrm{M}^{2+}\left(\mathrm{Mg}^{2+}\right.$, $\mathrm{Zn}^{2+}, \mathrm{Fe}^{2+}, \mathrm{Co}^{2+}, \mathrm{Cu}^{2+}$ and others $)$ and $\mathrm{M}^{3+}\left(\mathrm{Al}^{3+}, \mathrm{Cr}^{3+}, \mathrm{Fe}^{3+}, \mathrm{Ga}^{3+}\right.$ and others) occupy octahedral holes in a brucite-like layer, and the anion $\mathrm{A}^{n-}$ is located in the hydrated interlayer galleries. ${ }^{37}$ As an example of an LDH, Fig. 3 represents the plate structure of $\mathrm{Zn}-\mathrm{Al}-\mathrm{NO}_{3}-\mathrm{LDH}{ }^{38}$

The thickness of the LDH plates is usually about $30-50 \mathrm{~nm}$. Williams and McMurray prepared LDHs with different organic inhibitors (benzotriazolate, ethyl xanthate and oxalate). The resulting inhibitor-loaded LDHs were inserted into a poly(vinyl butyral) coating on top of an AA2024-T3 aluminium alloy. ${ }^{39}$ 


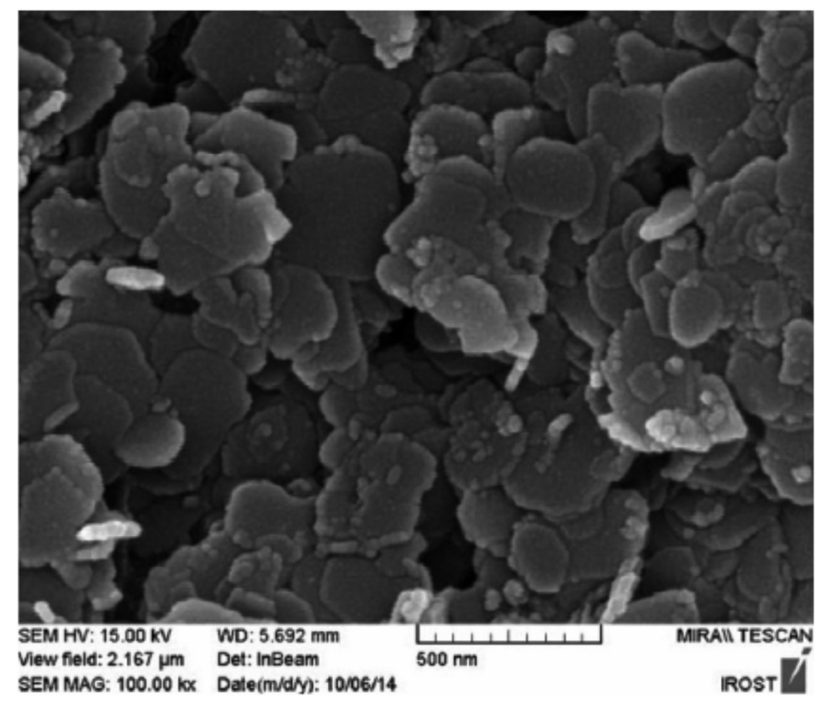

Fig. 3 SEM image of $\mathrm{Zn}-\mathrm{Al}-\mathrm{NO}_{3}-\mathrm{LDH}^{38}$

In another report, Kendig and Hon prepared LDHs intercalated with 2,5-dimercapto-1,3,4-thiadiazolate and studied the inhibiting properties of this anion with respect to the oxygen reduction reaction on copper. ${ }^{40} \mathrm{Zn}-\mathrm{Al}$ and $\mathrm{Mg}-\mathrm{Al} \mathrm{LDHs}$ loaded with quinaldate and 2-mercaptobenzothiazolate were synthesized via anion-exchange reaction. The coating barrier properties were found to be the best for LDH-doped primer. Poznyak et $a l^{41,42}$ showed active corrosion protection of aluminium alloy 2024-T3 for coatings with LDHs intercalated with 2-mercaptobenzothiazole and quinaldic acid.

An additional improvement of the self-healing activity can be achieved by using simultaneously inhibitor-loaded LDHs and cerium molybdate nanocontainers loaded with mercaptobenzothiazole added into epoxy primers, either individually or in a 1:1 combination. The evolution of the self-healing activity was studied by the scanning vibrating electrode technique (SVET) with a defect $(0.2 \mathrm{~mm}$ size) created in the coating prior to immersion into $0.05 \mathrm{M} \mathrm{NaCl}$ solution (Fig. 4).

The coating without nanocontainers revealed corrosion immediately after immersion in $0.05 \mathrm{M} \mathrm{NaCl}$ and the corrosion anodic current increased continuously with time without any self-healing effect. ${ }^{43}$ With the addition of a mixture of
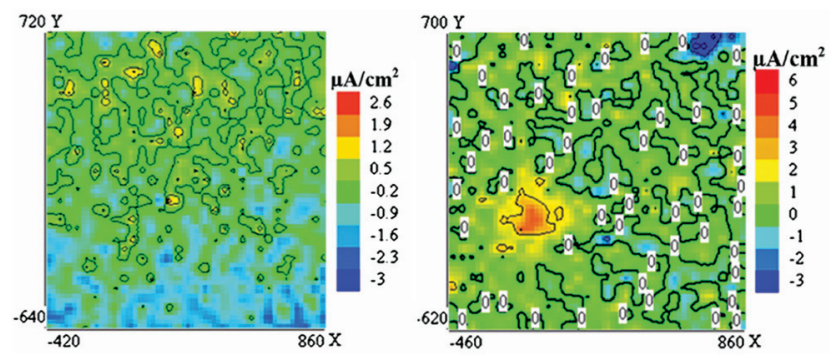

Fig. 4 Coating modified with a mixture of mercaptobenzothiazoleloaded LDH and cerium molybdate nanocontainers. Current density maps obtained at immersion times in $0.05 \mathrm{M} \mathrm{NaCl}$ : after $3 \mathrm{~h}$ (left) and after $40 \mathrm{~h}$ (right). ${ }^{43}$ mercaptobenzothiazole-loaded LDH and mercaptobenzothiazoleloaded cerium molybdate nanocontainers only almost negligible corrosion activity (red spot indicating anodic current, Fig. 4) was demonstrated after $40 \mathrm{~h}$ of immersion. These results can be explained by a synergetic inhibition effect that combines early corrosion protection and longer term inhibition. Such behaviour clearly demonstrates the potential of nanocontainer mixtures in the design of smart coatings with self-healing abilities for prolonged coating lifetimes. A similar synergetic effect was reported for only LDH nanocontainers but loaded with different inhibitors: vanadate, phosphate and 2-mercaptobenzothiazole. ${ }^{44}$ The combination of LDH nanocontainers loaded with vanadate and phosphate anions, and vanadate and mercaptobenzothiazole (MBT) anions conferred a significant improvement in corrosion protection on AA2024 aluminium alloy.

Hydrotalcite-based conversion films also demonstrated perfect corrosion protection. Hydrotalcites are typical anionexchange materials consisting of stacks of positively charged mixed hydroxide layers separated by anions and water molecules. An environmentally friendly corrosion inhibitor, phytic acid, was successfully added to the hydrotalcite film by adsorption and ion-exchange. ${ }^{45}$ The metal substrate used in this study was AZ31 Mg alloy. Compared with the original hydrotalcite film, the corrosion behaviour of the hydrotalcite film with intercalated phytic acid is much better. The resistance was notably higher than that of the original hydrotalcite film after $12 \mathrm{~h}$ immersion. The same group demonstrated the performance of molybdate intercalated into hydrotalcite particles for magnesium protection. ${ }^{46,47}$ By means of competitive adsorption, protective deposition and oxidation reactions, the released $\mathrm{MoO}_{4}{ }^{2-}$ ions acted as a good anodic inhibitor to protect $\mathrm{Mg}$ alloys from corrosion attacks.

The price for ion-exchange nanoclays as a nanocontainer host varies between 90 and 3600 USD per metric ton depending on the nature of the nanoclays (if they can be mined and directly used after purification or they have to be synthesized), composition (abundant or rare metals) and availability in large volumes. The abundance of the supply sources together with the low cost is the main advantage of ion-exchange nanoclays for application in industrial self-healing coatings. However, the main disadvantage is their low loading inhibitor capacity. Layered mineral clays can only load the corrosion inhibitor between their layers in a small, $0.5-2 \mathrm{~nm}$ sized lumen. This results in a low loading capacity of the clays, which is usually $5-8 \mathrm{wt} \%$. One needs to find the possibility of increase the loading capacity of the nanocontainers in order to prolong the service lifetime of selfhealing materials. The more corrosion inhibitor loaded into the containers, the larger the corrosion defect that can be healed. Ion-exchange nanocontainers can be used as a self-healing paint additive in water-based paints. However, the problem of the higher loading capacity should be solved in order to make ionexchange nanocontainers attractive for commercial applications.

\section{Halloysite nanocontainers}

Halloysite is a clay material that can be mined from deposits as a raw mineral (price range 6-10 USD per kg). ${ }^{48,49}$ Halloysite 

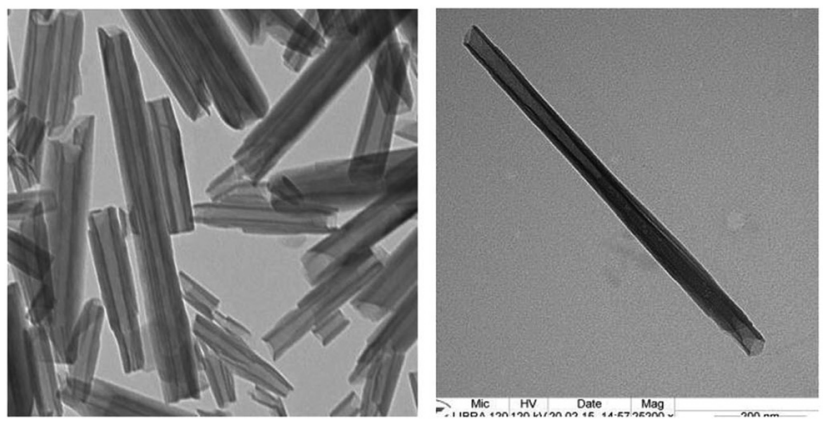

Fig. 5 TEM images of halloysite nanotubes. ${ }^{49}$

$\left(\mathrm{Al}_{2} \mathrm{Si}_{2} \mathrm{O}_{5}(\mathrm{OH})_{4} \cdot n \mathrm{H}_{2} \mathrm{O}\right)$ is a layered aluminosilicate chemically similar to kaolin which has a hollow tubular structure in the submicrometer range. The size of halloysite tubules varies in the range of 500-1000 $\mathrm{nm}$ in length and 15-100 $\mathrm{nm}$ in inner diameter depending on the deposit (Fig. 5).

A typical specific surface area of halloysite is $65 \mathrm{~m}^{2} \mathrm{~g}^{-1}$, pore volume is $1.3 \mathrm{~mL} \mathrm{~g}^{-1}$ and specific gravity is $2.53 \mathrm{~g} \mathrm{~cm}^{-3}$. The outermost surface of the halloysite is related to silica while the inner lumen surface may be compared to alumina. Below pH 8.5 the tubule lumen has a positive inner surface, enabling the loading of a negative corrosion inhibitor and preventing its adsorption on the negatively charged outer surface. The current world supply of halloysites is in excess of 50000 tons per year.

Inner halloysite lumen can provide additional space and an increased loading capacity for corrosion inhibitors up to $20 \mathrm{wt} \% .{ }^{50}$ Additional selective etching of the alumina inside the halloysite lumen with sulfuric acid can increase the lumen capacity and corrosion inhibitor loading up to $60 \mathrm{wt} \%{ }^{51}$ This loading capacity is close to the loading capacity of polymer nanocontainers. Besides corrosion inhibitors, halloysite can be a cargo for biocides and exploited in antifouling coatings. ${ }^{52,53}$ The typical procedure of the loading of halloysite nanotubes is as follows. ${ }^{54}$ Halloysites are mixed with a solvent possessing high solubility for the desired corrosion inhibitor and a low temperature boiling point. Then, the vial containing the solution is placed in a desiccator under vacuum, which deaerates the halloysite lumen. Due to the rapid evaporation of the solvent, the inhibitor concentration increases thus improving the loading efficiency.

Embedding the inhibitor-loaded halloysites into the coating requires intensive mixing of the dried halloysites with the coating formulation using high-speed stirrers, UltraTurrex or ultrasound. Formation of any aggregated nanocontainers will make defects in the coating integrity thus reducing the coating barrier properties. The halloysite should be homogeneously distributed on the coated area to protect every part of the metal substrate (Fig. 6).

The self-healing properties of benzotriazole and 8-hydroxyquinoline-loaded halloysite nanotubes were studied in zirconiasilica sol-gel coatings deposited on the surface of aluminium alloy A2024 by periodic measurements of SVET current density profiles. ${ }^{55}$ SVET observations on the aluminium plates coated with sol-gel films containing inhibitor-loaded halloysite revealed

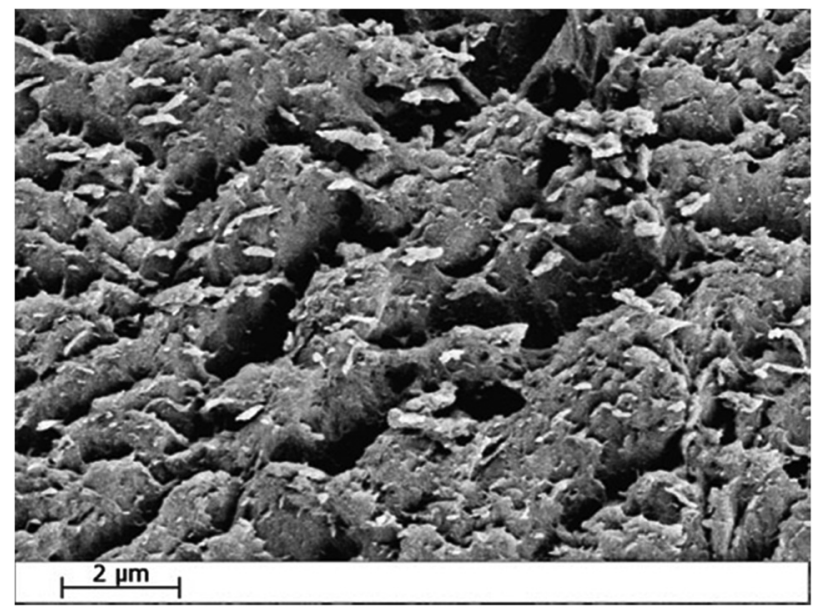

Fig. 6 Distribution of inhibitor-loaded halloysite nanotubes inside a solgel coating. ${ }^{55}$

the reduction of the maximal anodic current down to the noise level within $4.5 \mathrm{~h}$ of immersion in $0.1 \mathrm{M} \mathrm{NaCl}$.

Halloysite clay nanotubes loaded with corrosion inhibitors benzotriazole, mercaptobenzimidazole and mercaptobenzothiazole were used as additives in the self-healing composite paint coating of copper. ${ }^{56,57}$ The release rate of benzotriazole was controlled by the formation of metal-benzotriazole stoppers at the tube endings. This method provided a high halloysite loading efficiency and a long release time which gives additional possibilities for process optimization. Formation of the insoluble metal-benzotriazole complex was studied for $\mathrm{Cu}(\mathrm{II}), \mathrm{Fe}(\mathrm{II}), \mathrm{Fe}(\mathrm{III})$ and $\mathrm{Co}(\mathrm{II})$ ions. The efficiency of the halloysite lumen loading ascended in the order of benzotriazole $<$ mercaptobenzothiazole $<$ mercaptobenzimidazole.

Recently, another type of the ceramic nanotube called attapulgite was introduced as an alternative for halloysite nanocontainers. ${ }^{58}$ Attapulgite (ATP) is a hydrous layer-ribbon magnesium aluminium silicate with a fibrous structure and a theoretical formula of $\left(\mathrm{Al}_{2} \mathrm{Mg}_{2}\right) \mathrm{Si}_{8} \mathrm{O}_{20}(\mathrm{OH})_{2}\left(\mathrm{OH}_{2}\right)_{4} \cdot 4 \mathrm{H}_{2} \mathrm{O} .^{59}$ The ATP nanoparticles possess a fibre-shaped morphology with a size of approximately $0.8-1 \mu \mathrm{m}$ long and $20 \mathrm{~nm}$ in diameter. ATP is widely used as a reinforcement filler of nanocomposites, a catalyst carrier, and adsorbent. ATP was found to be a viable and inexpensive nanoscale container, and in industry the price of ATP is about 200 USD per ton. ${ }^{60}$

Despite the large number of papers devoted to nanocontainerbased self-healing coatings, most of them use lab-scale analytical methods for characterization of their self-healing performance. The current level of the development of nanocontainer-based self-healing coatings requires the study of their industrial applications. Anticorrosion performance tests using the industrial neutral salt-spray test (ISO 9227 standard, 5 wt $\% \mathrm{NaCl}$, $35{ }^{\circ} \mathrm{C}$ ) have been conducted to check halloysite efficiency in industrial coatings. ${ }^{61,62}$

A standard commercial polyepoxy coating was used for comparison. As one can see in Fig. 7, the direct addition of Korantin SMK corrosion inhibitor, which is an alkylphosphoric ester produced by BASF with an alkyl chain length in the ester 


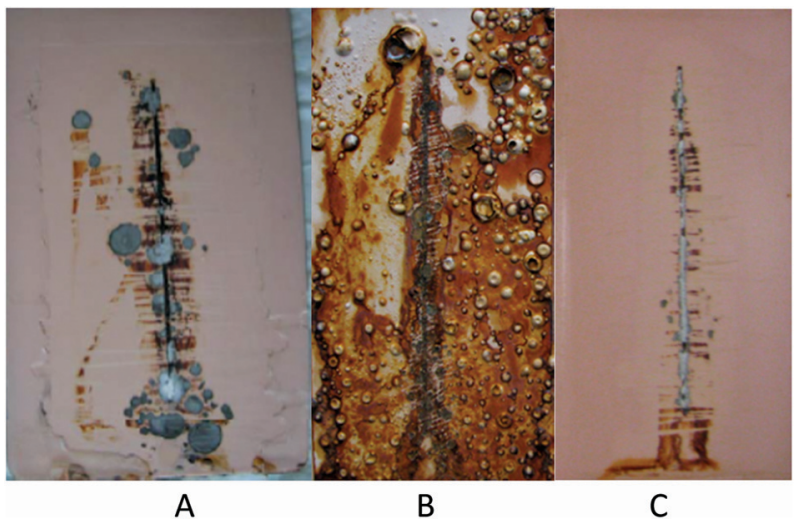

Fig. 7 Neutral salt-spray test results for pure polyepoxy coating (A, $1000 \mathrm{~h}$ ), polyepoxy coating directly loaded with Korantin SMK corrosion inhibitor $(\mathrm{B}, 500 \mathrm{~h})$ and polyepoxy coating in the presence of Korantin SMK-loaded halloysite nanotubes $(\mathrm{C}, 1000 \mathrm{~h}){ }^{62}$

group ranging from $\mathrm{C} 6$ to $\mathrm{C} 10$, into the coating in free form ( $1 \mathrm{wt} \%$ ) drastically reduces the corrosion protection performance after $500 \mathrm{~h}$ of the neutral salt-spray test. On the contrary, using the inhibitor encapsulated inside halloysite nanotubes increased the corrosion protection by five times. This is clear evidence on the industrial level, employing a widely known saltspray industrial test, that halloysite nanotubes can develop a new, revolutional generation of self-healing anticorrosion coatings. Currently, halloysite nanotubes have the best prospects to be included as an additive in current paint formulations for commercial applications.

\section{Multifunctional nanocontainers}

The multiple functionality of the coatings is limited by the amount of nanocontainers (capsules) which can be incorporated into the coatings without changing their main properties like barrier, colour, etc. Usually, if the amount of nanocontainers exceeds $10 \mathrm{wt} \%$ in the cured coating, its main passive functionalities become considerably reduced. ${ }^{63}$ Therefore, the second generation of multifunctional nanocontainer based coatings should not have a combination of the nanocontainers with a single functionality, but involve nanocontainers with multiple functionalities. This direction is rapidly developing now with an increasing number of publications.

Multifunctional nanocontainers can be divided into two types. The first type has a shell which is sensitive to the several (two or more) triggers. The second one can contain cargo with either several functionalities or a combination of the primary functionality of the cargo with the secondary functionality of the shell.

One of the most developed combinations is the use of several corrosion inhibitors in one nanocontainer. A combination of corrosion inhibitors that are active under different conditions (e.g., pH, temperature) can provide a synergetic effect for the self-healing efficiency of the coatings. Composite cerium molybdate nanocontainers have been synthesized and then loaded with 8-hydroxyquinoline or with 1- $H$-benzotriazole4-sulfonic acid. ${ }^{64}$ Application of cerium molybdate nanocontainers loaded with mercaptobenzothiazole ( $58 \mathrm{wt} \%$ ) have also been shown for the protection of magnesium alloys. ${ }^{65}$ A spontaneous emulsification method was exploited to prepare mesoporous $\mathrm{CeO}_{2} @ \mathrm{SiO}_{2}$ hybrid particles for the corrosion protection of aluminium. ${ }^{66}$ To complement $\mathrm{CeO}_{2}$ corrosion inhibition, 8-hydroxyquinoline was used, which is an effective anodic inhibitor that exhibited synergistic effects with Ce-containing compounds. These two encapsulated inhibitors provided the effective corrosion protection of aluminium by two mechanisms: the initial burst of encapsulated 8-hydroxyquinoline followed by the sustained release of $\mathrm{Ce}$ ions. Hollow $\mathrm{CeO}_{2}$ nanocontainers were prepared as reservoirs for loading the benzotriazole (BTA) inhibitor. Then, the loaded $\mathrm{CeO}_{2}$ nanocontainers were coated with polyelectrolyte multilayers in a layer-by-layer deposition approach to form a core-shell structure of $\mathrm{CeO}_{2} / \mathrm{BTA} /$ (polyethyleneimine, $\mathrm{PEI} /$ polystyrene sulphonate, $\mathrm{PSS})_{2} \cdot{ }^{67}$ The modified $\mathrm{CeO}_{2}$ nanocontainers were incorporated into the epoxy coating at a concentration of $0.5 \mathrm{wt} \%$. The release curve at $\mathrm{pH} 7$ demonstrates control of the PEI/PSS polyelectrolyte shell over the spontaneous release of BTA, avoiding undesirable leakage due to its weak permeability properties in the neutral aqueous conditions (Fig. 8). When the $\mathrm{pH}$ values change to acidic or alkaline conditions, the BTA molecules are released from the nanocontainers much faster. This is attributed to the polyelectrolyte shells with weak acidic or basic ionisable functional groups. These groups can demonstrate reversible and/or irreversible changes of the shell permeability over a wide $\mathrm{pH}$ region (e.g. at low $\mathrm{pH}<4$ and high $\mathrm{pH}>9) .{ }^{68}$ Scanning Kelvin probe maps of Volta potential distribution after immersion in $0.5 \mathrm{M} \mathrm{NaCl}$ demonstrated no corrosion effects around the defect of the coating containing the double-inhibiting nanocontainers.

Multishelled capsules containing linseed oil as themain core inhibitor and benzotriazole between the polyelectrolyte multilayers were prepared by combination of in situ polymerisation and a polyelectrolyte layer-by-layer assembly technique. ${ }^{69}$

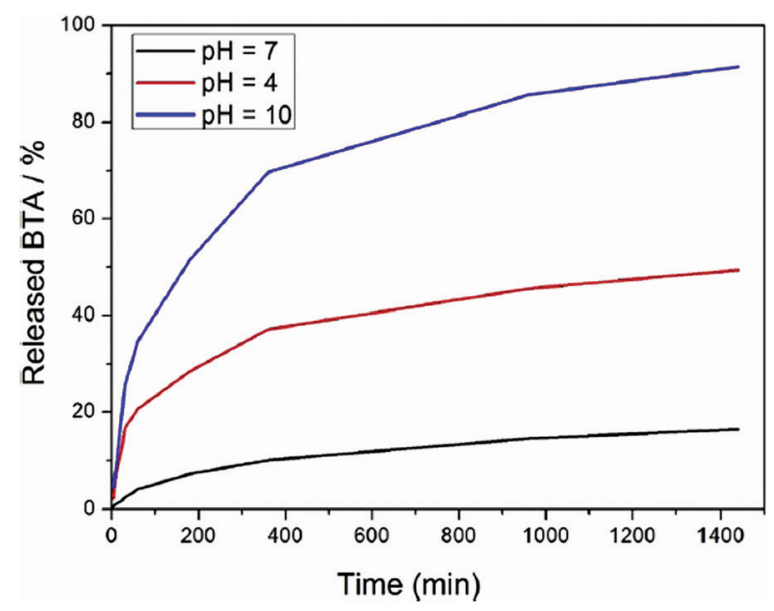

Fig. 8 BTA release profiles from $\mathrm{CeO}_{2} / \mathrm{BTA} /(\mathrm{PEI} / \mathrm{PSS})_{2}$ nanocontainers. ${ }^{67}$ 
FTIR analyses and zeta potential measurements confirmed the encapsulation of the linseed oil inside and the effective adsorption of alternate layers of polyethyleneimine, polystyrene sulphonate and benzotriazole in the shell. Electrochemical impedance spectroscopy analysis of coated AISI 1020 carbon steel showed a pronounced self-healing effect of the epoxy resin loaded with $4.8 \mathrm{wt} \%$ of double stimuli-responsive capsules.

Novel benzotriazole-loaded nanocontainers with additional shell functionality were developed using a tannic acid-Fe(III) complex (TAC) as the shell and benzotriazole as the loaded inhibitor. $^{70}$ The deposition of TAC as a shell for BTA-loaded nanocontainers takes only $20 \mathrm{~s}$. Electrochemical impedance of the blank coating presented a downward trend over 20 days. In terms of coatings with nanocontainers-BTA@TAC, the impedance modulus at $0.01 \mathrm{~Hz}$ increased from $4.7 \times 10^{4} \Omega \mathrm{cm}^{2}$ to $1.8 \times 10^{5} \Omega \mathrm{cm}^{2}$. Both the released BTA and the detached tannic acid from the surface of mesoporous silica nanoparticles contributed to the self-healing effect of the coatings.

Triple-action self-healing polymer coatings were developed by incorporation of dual-function capsules containing polycaprolactone (PCL) and the corrosion inhibitor 8-hydroxyquinoline (8HQ) into a shape memory polymer (SMP) coating. ${ }^{71}$ The results demonstrated that the coating possessed a triple-action selfhealing ability that was enabled by the cooperation of the $8 \mathrm{HQ}$ inhibitor, the SMP coating matrix, and the melted microspheres. The coating released $8 \mathrm{HQ}$ (inhibitor loading was $21 \mathrm{wt} \%$ ) in a pH-dependent fashion and immediately suppressed corrosion within the coating scratch. After heat treatment, the scratched coating exhibited excellent recovery of its anticorrosion performance attributed to the simultaneous initiation of scratch closure by the shape memory effect of the coating matrix together with sealing of the scratch by the melted microspheres.

As shown in Fig. 9, the capsules hold the corrosion inhibitor which is released from the capsules and suppresses corrosion when the coating is damaged. When heat is applied, the shape memory effect induces the closure of the coating scratch, which is further sealed by the simultaneous melting of the PCL shell of the capsules. Coatings containing 5,10 , and $15 \mathrm{wt} \%$ capsules exhibited a repaired barrier effect after heating at $80{ }^{\circ} \mathrm{C}$ for $30 \mathrm{~min}$. The full recovery of the barrier properties of the coating was attributed to not only the closure of the scratch by the shape memory effect but also to the sealing of the remaining gaps by the melted PCL capsules. An optimum quantity of $10 \mathrm{wt} \%$ microspheres was defined by assessing the morphology and barrier properties of the coatings. The presence of the corrosion inhibitor $8 \mathrm{HQ}$ is necessary to passivate the underneath surface of the $\mathrm{Al}$ substrate before crack closure with polymer components of the coating in order to prevent further interaction with the corrosive species, which can diffuse through the healed/initial interface of the coating.

Multifunctional encapsulation in nanocontainers can be challenging when the organic chemical species to be encapsulated have different polarities. ${ }^{72}$ A new design for nanocontainers that allows for a selective release of one encapsulated agent by a $\mathrm{pH}$ change and another agent by the chemical reduction of the nanocontainer shell is demonstrated by Landfester and Crespy. ${ }^{73}$ Polyaniline (PANI) was selected as the material to build the shell of the nanocontainers. The PANI structure has the important advantage of being both redox- and $\mathrm{pH}$-responsive. The two selected corrosion inhibitors were 3-nitrosalicylic acid (3-NisA) and 2-mercaptobenzothiazole (MBT). The first molecule has a $\mathrm{p} K_{\mathrm{a}}$ value around 3 and therefore its solubility can be controlled by the $\mathrm{pH}$ whereas the second molecule can be attached to the covering gold surface and then later released electrochemically. The strategy for the multifunctional release of the two inhibitors is represented in Fig. 10.

The PANI/3-NisA nanocontainers were then successfully decorated with gold nanoparticles (AuNPs, $\sim 20 \mathrm{~nm}$ diameter) by electrostatic adsorption. The presence of the gold nanoparticles on the PANI shell allows for a stable electronic contact between the capsules and a metal substrate and, at the same time, the presence of the gold nanoparticles on the shell provides a possibility for loading of MBT via gold-thiol bonds. Two encapsulated inhibitors can be released selectively and independently by activating the nanocontainers, either by $\mathrm{pH}$ change or by electrochemical reduction. A similar approach

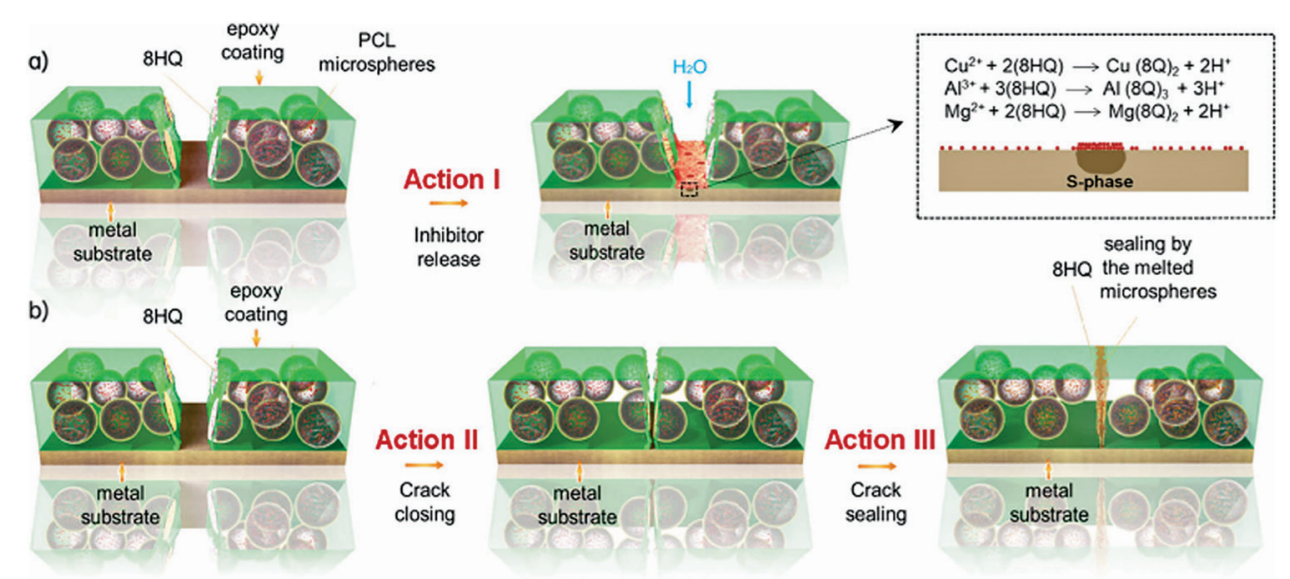

Fig. 9 Triple self-healing mechanism performed by (a) $8 \mathrm{HQ}$ released from PCL capsules for local corrosion inhibition, (b) synergetic effect of crack closing by the shape memory epoxy polymer and crack sealing by the melted PCL capsules. ${ }^{71}$ 


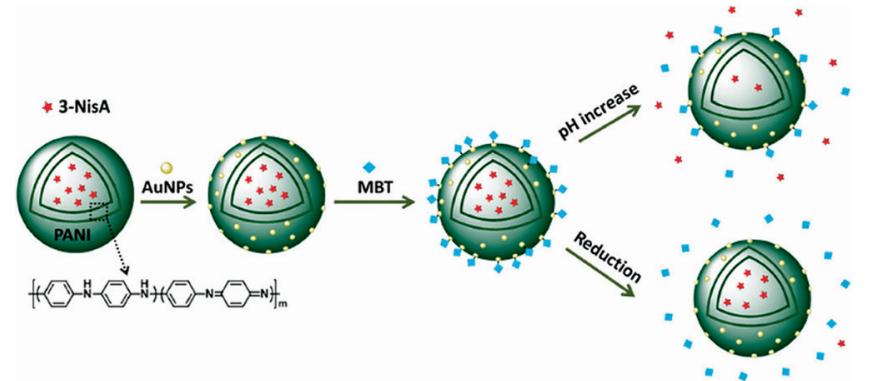

Fig. 10 Scheme representing the formation of the dual-delivery nanocontainers and the subsequent selective release of the corrosion inhibitors upon $\mathrm{pH}$ change or reduction. ${ }^{73}$

was explored for designing nanocontainers allowing the release of two corrosion inhibitors with different release mechanisms. ${ }^{74}$ The first corrosion inhibitor, MBT, was covalently bound to the shell of the nanocontainers. The second one, polydimethylsiloxane diglycidyl ether as a hydrophobic healing agent, was physically entrapped in the core of the nanocontainers. The release of the two self-healing agents was triggered by reduction of the polymeric shell and the release rate actually depended on the chemical nature of the hydrophobic healing agent and the chemical structure of the shell. Additionally, the release of the MBT from the nanocontainer shell allows for the release of the entrapped hydrophobic self-healing agent yielding a cascade release of the two inhibitors. The multifunctionalisation of the coatings and nanocontainers is a new research direction which can make a new generation of coatings similar to the skin; however, a lot of the research efforts are needed in this area.

\section{Conclusions}

The concept of the nanocontainer-based self-healing coatings has gained increasing interest among researchers since our first Highlight paper published in 2011 (Chem. Commun., $2011,47,8730)$. The number of publications in this area has increased from 80 in 2011 to $>300$ in 2017 according to the WoS database ("self-healing coatings" was selected as the topic for the literature search). The main advantage of such self-healing coatings is their autonomic response to corrosion or any other defects in the coating. After the damage is healed, the release of the encapsulated active agents stops and the coating restores its characteristics.

This approach has been demonstrated by numerous publications about coatings with nanocontainers with a single function like the release of one corrosion inhibitor using one triggering mechanism. There is a great challenge to extend this approach to the development of multifunctional nanocontainers that are able to encapsulate several active materials and respond to different triggering impacts. This can attain the coating's autonomic multifunctionality reacting to the various environmental changes. A lot of the research work has to be done in this area, mostly focusing on the mechanisms of the coating matrix-shell and nanocontainer-nanocontainer interactions. This will require more efforts in the development of new shell components and a decrease of the nanocontainer size whilst maintaining, at the same time, a high loading capacity.

Another challenge is the transformation of the current research achievements to the technology level. There has been more than 15 years of research in this area and now the time is critical to transfer the lab results to practical applications. This work requires close collaboration with paint producers to adapt developed nanocontainers to the commercial paint formulations and industrial tests. Unfortunately, $80 \%$ of the lab results cannot find real industrial application, mostly because of the high costs, complexity and low stability of the studied nanocontainers in paint formulations. A high ratio between the container size and the coating thickness can result in the loss of physical integrity of the coating matrix. The nanocontainer shell has to provide good adhesion between the containers and host matrix as well as many other properties which are mostly omitted during laboratory research. However, several lab-industry collaborations (e.g., with BASF, Enviral, EADS, Smallmatek. Shandong GEWU New Material Technology) already exist in UK, USA, EU, China and Russia, resulting in a few prototypes and even nanocontainer-based self-healing coatings on the market.

Nanocontainer-based coatings have enormous prospects both from commercial and scientific points of view. Current commercialization examples already showed successful niches for nanocontainer-based coatings becoming more and more attractive compared with conventional coatings for end users. Existing scientific challenges are the development of multifunctional nanocontainers, the study of the interactions between nanocontainers, and the influence of nanocontainer position across the coating film on the self-healing performance. The nanocontainer technologies developed for self-healing coatings can also be used for other smart materials.

\section{Conflicts of interest}

There are no conflicts to declare.

\section{Acknowledgements}

The work was supported by ERC Consolidator grant ENERCAPSULE (project 647969) and ERC Proof-of-Concept grant ENERPAINT (project 767173). This article is dedicated to the memory of Professor Helmuth Möhwald, one of the co-founders of the Max Planck Institute of Colloids and Interfaces and the only leader of the Department of Interfaces in MPI-KGF.

\section{Notes and references}

1 D. G. Shchukin and H. Möhwald, Science, 2013, 341, 1458.

2 D. G. Shchukin and H. Möhwald, Small, 2007, 3, 926.

3 S. R. White, N. R. Sottos, P. H. Geubelle, J. S. Moore, M. R. Kessler, S. R. Sriram, E. N. Brown and S. Viswanathan, Nature, 2001, 409, 794.

4 M. W. Keller, S. R. White and N. R. Sottos, Adv. Funct. Mater., 2007, 17, 2399.

5 M. M. Caruso, B. J. Blaiszik, S. R. White, N. R. Sottos and J. S. Moore, Adv. Funct. Mater., 2008, 18, 1898.

6 X. He and X. Shi, Prog. Org. Coat., 2009, 65, 37. 
7 H. Liu, E. Gnade and K. J. Balkus, Smart Coatings III, ACS Symposium Series, 2010, ch. 3, p. 31.

8 C. Suryanarayana, K. C. Rao and D. Kumar, Prog. Org. Coat., 2008, 63, 72 .

9 D. G. Shchukin and G. B. Sukhorukov, Adv. Mater., 2004, 16, 671.

10 A. Latnikova, D. O. Grigoriev, J. Hartmann, H. Möhwald and D. G. Shchukin, Soft Matter, 2011, 7, 369.

11 A. Latnikova, D. O. Grigoriev, H. Möhwald and D. G. Shchukin, Polymer, 2015, 73, 183.

12 M. M. Boyle, R. A. Smaldone, A. C. Whalley, M. W. Ambrogio, Y. Y. Botros and J. F. Stoddart, Chem. Sci., 2011, 2, 204.

13 S. Angelos, N. M. Khashab, Y. W. Yang, A. Trabolsi, H. A. Khatib, J. F. Stoddart and J. I. Zink, J. Am. Chem. Soc., 2009, 131, 12912.

14 Z. Zheng, X. Huang, M. Schenderlein, H. Möhwald, G. K. Xu and D. G. Shchukin, Nanoscale, 2015, 7, 2409.

15 Z. Zheng, M. Schenderlein, X. Huang, N. J. Brownbill, F. Blanc and D. G. Shchukin, ACS Appl. Mater. Interfaces, 2015, 7, 22756.

16 A. M. Javier, P. de Pino, M. F. Bedard, D. Ho, A. G. Skirtach, G. B. Sukhorukov, C. Planck and W. J. Parak, Langmuir, 2008, 24, 12517.

17 E. V. Skorb, A. G. Skirtach, D. V. Sviridov, D. G. Shchukin and H. Möhwald, ACS Nano, 2009, 3, 1753.

18 X. Tao, J. B. Li and H. Möhwald, Chem. - Eur. J., 2004, 10, 3397.

19 E. V. Skorb, D. G. Sviridov, H. Möhwald and D. G. Shchukin, Chem. Commun., 2009, 6041.

20 D. G. Shchukin, D. A. Gorin and H. Möhwald, Langmuir, 2006, 22, 7400 .

21 K. Köhler, D. G. Shchukin, H. Möhwald and G. B. Sukhorukov, J. Phys. Chem. B, 2005, 109, 18250.

22 A. A. Antipov and G. B. Sukhorukov, Adv. Colloid Interface Sci., 2004, 111, 49.

23 L. P. Lv, S. Jiang, A. Inan, K. Landfester and D. Crespy, RSC Adv., 2017, 7, 8272.

24 D. G. Shchukin, K. Kohler and H. Möhwald, J. Am. Chem. Soc., 2006, 128, 4560 .

25 A. Vimalanandan, L. P. Lv, T. H. Tran, K. Landfester, D. Crespy and M. Rohwerder, Adv. Mater., 2013, 25, 6980.

26 D. G. Shchukin and H. Möhwald, Chem. Commun., 2011, 47, 8730.

27 D. Borisova, H. Möhwald and D. G. Shchukin, ACS Nano, 2011, 5, 1939.

28 I. A. Kartsonakis, I. L. Danilidis, G. S. Pappas and G. Kordas, J. Nanosci. Nanotechnol., 2010, 10, 5912.

29 J. Tedim, M. L. Zheludkevich, A. N. Salak, A. Lisenkov and M. G. S. Ferreira, J. Mater. Chem., 2011, 21, 15464.

30 Y. Lvov, W. Wang, L. Q. Zhang and R. Fakhrullin, Adv. Mater., 2016, $28,1227$.

31 T. L. P. Galvão, C. S. Neves, A. P. F. Caetano, F. Maia, D. Mata, E. Malheiro, M. J. Ferreira, A. C. Bastos, A. N. Salak, J. R. B. Gomes, J. Tedim and M. G. S. Ferreira, J. Colloid Interface Sci., 2016, 468, 86.

32 G. Cavallaro, G. Lazzara and R. Fakhrullin, Ther. Delivery, 2018, 9, 287.

33 S. Bohm, H. N. McMurray, S. M. Powell and D. A. Worsley, Mater. Corros., 2001, 52, 896.

34 H. N. McMurray, D. Williams, G. Williams and D. Worsley, Corros. Eng., Sci. Technol., 2003, 38, 112.

35 A. Ghazi, E. Ghasemi, M. Mahdavian, B. Ramezanzadeh and M. Rostami, Corros. Sci., 2015, 94, 207.

36 F. Miccichè, H. Fischer, R. Varley and S. van der Zwaag, Surf. Coat. Technol., 2008, 202, 3346.

37 G. R. Williams and D. O'Hare, J. Mater. Chem., 2006, 16, 3065.

38 E. Alibakhshi, E. Ghasemi, M. Mahdavia and B. Ramezanzadeh, Corros. Sci., 2017, 115, 159.

39 G. Williams and H. N. McMurray, Electrochem. Solid-State Lett., 2004, $7,13$.

40 M. H. Kendig and M. Hon, Electrochem. Solid-State Lett., 2005, 8, 10.

41 M. L. Zheludkevich, S. K. Poznyak, L. M. Rodrigues, D. Raps, T. Hack, L. F. Dick, T. Nunes and M. G. S. Ferreira, Corros. Sci., 2010, 52, 602.
42 S. K. Poznyak, J. Tedim, L. M. Rodrigues, A. N. Salak, M. L. Zheludkevich, L. F. P. Dick and M. G. S. Ferreira, ACS Appl. Mater. Interfaces, 2009, 1, 2353.

43 M. F. Montemor, D. V. Snihirova, M. G. Taryba, S. V. Lamaka, I. A. Kartsonakis, A. C. Balaskas, G. C. Kordas, J. Tedim, A. Kuznetsova, M. L. Zheludkevich and M. G. S. Ferreira, Electrochim. Acta, 2012, 60, 31.

44 J. Tedim, S. K. Poznyak, A. Kuznetsova, D. Raps, T. Hack, M. L. Zheludkevich and M. G. S. Ferreira, ACS Appl. Mater. Interfaces, 2010, $2,1528$.

45 R. B. Leggat, S. A. Taylor and S. R. Taylor, Colloids Surf., A, 2002, 210, 83.

46 J. Chen, Y. Song, D. Shan and E.-H. Han, Corros. Sci., 2013, 74, 130.

47 R.-C. Zeng, Z.-G. Liu, F. Zhang, S. Q. Li, H.-Z. Cui and E.-H. Han, J. Mater. Chem. A, 2014, 2, 13049.

48 Y. M. Lvov, D. G. Shchukin, H. Möhwald and R. R. Price, ACS Nano, 2008, 2, 814

49 Y. Lvov, W. Wang, L. Zhang and R. Fakhrullin, Adv. Mater., 2016, 28, 1227.

50 E. Joussein, S. Pitit, J. Churchman, B. Theng, D. Righi and B. Delvaux, Clay Miner., 2005, 40, 383.

51 R. Price, B. Gaber and Y. Lvov, J. Microencapsulation, 2001, 18, 713.

52 E. Abdullayev, A. Joshi, W. B. Wei, Y. F. Zhao and Y. Lvov, ACS Nano, 2012, 6, 7216.

53 Y. Lvov and R. Price, in Bio-Inorganic Hybrid Nanomaterials, ed. E. Ruiz-Hitzky, K. Ariga and Y. Lvov, Wiley, London, Berlin, 2007, ch. 12 , pp. 419-441.

54 Y. M. Lvov, D. G. Shchukin, H. Möhwald and R. R. Price, ACS Nano, 2008, 2, 814 .

55 D. Fix, D. V. Andreeva, Y. M. Lvov, D. G. Shchukin and H. Möhwald, Adv. Funct. Mater., 2009, 19, 1720.

56 E. Abdullayev, R. Price, D. Shchukin and Y. Lvov, ACS Appl. Mater. Interfaces, 2009, 1, 1437.

57 E. Abdullayev, V. Abbasov, A. Tursunbayeva, V. Portnov, H. Ibrahimov, G. Mukhtarova and Y. Lvov, ACS Appl. Mater. Interfaces, 2013, 5, 4464.

58 X. Liu, D. Zhang, P. Hou, J. Pan, X. Zhao and B. Hou, J. Electrochem. Soc., 2018, 165, 907.

59 X. Y. Li, D. Y. Zhang, X. Q. Liu, L. Y. Shi and L. B. Sun, Chem. Eng. Sci., 2016, 141, 184.

60 H. Yin and J. Zhu, Chem. Eng. J., 2016, 285, 112.

61 E. Shchukina, D. G. Shchukin and D. Grigoriev, Prog. Org. Coat., 2018, 123, 384.

62 E. Shchukina, D. Grigoriev, T. Sviridova and D. G. Shchukin, Prog. Org. Coat., 2017, 108, 84.

63 D. Grigoriev, E. Shchukina and D. G. Shchukin, Adv. Mater. Interfaces, 2017, 4, 1600318.

64 I. A. Kartsonakis and G. Kordas, J. Am. Ceram. Soc., 2010, 93, 65.

65 I. A. Kartsonakis, A. C. Balaskas, E. P. Koumoulos, C. A. Charitidis and G. Kordas, Corros. Sci., 2012, 65, 481.

66 M. J. Hollamby, D. Borisova, H. Möhwald and D. G. Shchukin, Chem. Commun., 2012, 48, 115.

67 X. Liu, C. Gu, Z. Wen and B. Hou, Prog. Org. Coat., 2018, 115, 195.

68 N. Y. Abu-Thabit and A. S. Hamdy, Surf. Coat. Technol., 2016, 303, 406.

69 D. A. Leal, I. C. Riegel-Vidotti, M. G. C. Ferreira and C. E. B. Marino, Corros. Sci., 2018, 130, 56.

70 B. Qian, M. Michailidis, M. Bilton, T. Hobson, Z. Zheng and D. Shchukin, Electrochim. Acta, 2019, 297, 1035.

71 Y. Huang, L. Deng, P. Ju, L. Huang, H. Qian, D. Zhang, X. Li, H. A. Terryn and J. M. C. Mol, ACS Appl. Mater. Interfaces, 2018, 10, 23369.

72 S. Aryal, C.-M. J. Hu and L. Zhang, Small, 2010, 6, 1442.

73 L. P. Lv, K. Landfester and D. Crespy, Chem. Mater., 2014, 26, 3351.

74 Y. Zhao, R. Berger, K. Landfester and D. Crespy, Small, 2015, 11, 2995. 